\title{
BIOÉTICA E TRANSHUMANISMO: UMA DISCUSSÃO SOBRE AS PESSOAS COM DEFICIÊNCIA E A IDEIA DE CIBORGUE
}

\author{
BIOETHICS AND TRANSHUMANISM: A DISCUSSION ABOUT PEOPLE WITH \\ DISABILITIES AND THE IDEA OF CYBORG
}

Recebido: 09.05.2020

\begin{abstract}
Raimundo Wilson Gama Raiol
Doutor em Direito pela Universidade Federal do Pará. Professor do Programa de Pós-graduação em Direito da Universidade Federal do Pará E-MAIL: raimundoraiolraiol@bol.com.br LATTES: http://lattes.cnpq.br/6271053538285645 ORCID: http://orcid.org/0000-0003-2407-1375
\end{abstract}

Aprovado: 27.04.2020

\author{
Evandro Luan de Mattos Alencar \\ Mestre em Direito pela Universidade Federal do \\ Pará. Advogado. \\ E-MAIL: alencar.ufpa@gmail.com \\ LATTES: http://lattes.cnpq.br/3430474424472893 \\ ORCID: http://orcid.org/0000-0002-7497-1745
}

\begin{abstract}
RESUMO: $O$ presente trabalho trata de abordar a discussão bioética sobre o transhumanismo, tema circundado pelas questões do progresso biotecnológico e o uso da ciência para as melhorias das capacidades, e a superação dos limites biológicos humanos. $\mathrm{O}$ problema enfrentado trata de responder os dilemas morais do avanço tecnológico e o redimensionamento da pessoa com deficiência no contexto futurista da hibridização entre homem e máquina. O objetivo consiste em analisar o cenário teórico e prático abordados pela bioética e pelo transhumanismo em relação as pessoas com deficiência. Para tal, adotarse-á a metodologia de pesquisa sócio-jurídica, de viés qualitativo.
\end{abstract}

PALAVRAS-CHAVE: transhumanismo; pessoas com deficiência; dignidade pós-humana; bionismo; ciborgue.

\begin{abstract}
The present work deals with addressing the bioethical discussion about transhumanism, a theme surrounded by issues of biotechnological progress and the use of science to improve capacities, and to overcome human biological limits. The problem faced tries to answer the moral dilemmas of technological advancement and the resizing of the person with disabilities in the futuristic context of the hybridization between man and machine. The objective is to analyze the theoretical and practical scenario addressed by bioethics and transhumanism in relation to people with disabilities. To this end, the methodology of socio-legal research, with qualitative bias, will be adopted.
\end{abstract}

KEYWORDS: transhumanism; disabled people; post-human dignity; bionism; cyborg.

SUMÁRIO: 1 Introdução 2 Paradigmas da Bioética e o Transhumanismo 3 Transhumanismo e o sujeito pós-humano 4 Cibercultura e a ideia do ciborgue 5 Cibertecnologia e a pessoa com deficiência 6 Conclusão 7 Referências 


\section{Introdução}

O presente trabalho trata de abordar a questão bioética sobre os debates trazidos pela corrente do transhumanismo, no que se refere, especificamente, a figura do ciborgue e a modificação da condição de capacidade de pessoas com deficiência, as quais passam a ter, com o suporte biotecnológico, novas possibilidades, como super habilidades e modificações nos seus corpos que podem alterar significativamente seus planos de vida e dignidade.

A bioética, como se sabe, é um recente campo de estudo que busca regulamentar a ética científica ligada ao avanço biotecnológico e sua correlação com a dignidade humana. Por sua vez, o transhumanismo se apresenta como uma corrente político-ideológica futurista que defende em seus pressupostos éticos a superação dos limites biológicos do homem.

Nesse cenário, são temáticas que enfrentam o problema comum da era biotecnocientífica e seus dilemas éticos proporcionados pelo progresso científico e desenvolvimento tecnológico, os quais impõe novas relações sociais e culturais ao homem. É um panorama que oferece, não somente melhorias objetivas a qualidade de vida humana, com também incertezas em relação ao futuro da humanidade.

Por conseguinte, as pessoas com deficiência se apresentam como segmento interessado nos avanços proporcionados pelas áreas da medicina, da biônica e da cibernética, ciências as quais proporcionam ou prometem condições de vida diferenciadas para essas pessoas e as possibilitam a sua inserção no centro de um atual debate biotecnológico.

O aperfeiçoamento de tecnologias assistivas e de equipamentos de reabilitação, como exoesqueletos, próteses e membros biônicos, implicam no surgimento de um hibridismo entre homem e máquina em um patamar nunca antes percebido. Esse panorama cria e insere no espaço social a figura do ciborgue, que trata-se de um ser orgânico com traços de tecnologia cibernética e perfeita sincronia, fato este que evidencia a gênese do denominado sujeito póshumano.

A justificativa para esse trabalho se dá pela necessidade de debater uma tema atual e relevante que é retratado com muita escassez na literatura nacional especializada e, principalmente, almeja inserir nesse cenário de novas discussões o protagonismo das pessoas com deficiência na formação do futuro consenso quanto ao direito de escolha e modificações sobre o próprio corpo, que implicam diretamente na determinação de suas capacidades e na liberdade morfológica. O objetivo consiste em analisar o cenário teórico e prático abordados pela bioética e pelo transhumanismo em relação as pessoas com deficiência e a sua relação com as novas possibilidades ofertadas pela promessa da inovação tecnológica.

Sendo assim, o problema enfrentado nesse ensaio consiste em buscar respostas na bioética e no transhumanismo para os dilemas morais enfrentados pelo futuro biotecnológico em relação as pessoas com deficiência e o seu redimensionamento social nesse espaço futurista que permite a hibridização entre homem e máquina. Para alcançar uma respostas sobre tal questão, propõe-se dissertar sobre o estado da arte da bioética e sua conexão com o transhumanismo, a construção do sujeito pós-humano e a ideia do ciborgue e, por fim, a inserção da pessoa com deficiência no debate sobre cibertecnologia.

Sobre a metodologia, realizar-se- á pesquisa qualitativa ou sócio jurídica, conforme compreende McConville e Chui $(2007$, p. 77) como aquela que busca descrever, explicar e criticar os fenômenos jurídicos de maneira interdisciplinar, com fulcro de encontrar respostas ao problema em discussão. Além disso, a coleta de dados se dará por meio de levantamento documental e bibliográfico, aquela que, segundo Severino (2010, p. 122) se utiliza de categorias 
e fontes já trabalhadas pela literatura especializada em revistas científicas, obras técnicas, documentos e legislações pertinentes.

O presente trabalho desenvolver-se-á a partir de quatro tópicos, a saber: o primeiro trata sobre os paradigmas da bioética e o transhumanismo, o segundo aborda a questão do transhumanismo e a constituição do sujeito pós-humano, o terceiro tópico abordará a questão da cibercultura e a construção imaginária da ideia do ciborgue e, em seguida, o último tópico dissertar-se-á sobre o debate que envolve as pessoas com deficiência e o avanço da cibertecnologia.

\section{Paradigmas da Bioética e o Transhumanismo}

É sabido que os temas ligados ao progresso científico, médico e tecnológico sempre apresentaram discussões sob as mais diversas perspectivas morais, o que implica no enfrentamento e debate de problemas correlatos, principalmente, a condição humana e seu núcleo protetivo de dignidade.

São questões geralmente apresentadas por filósofos, pensadores e cientistas que dissertam sobre esses dilemas e suas particularidades com intuito de oferecer orientações minimamente éticas para a conduta humana frente a novos questionamentos trazidos pelo contexto de avanço biotecnocientífico.

Nesse panorama, a bioética se apresenta como recente área do conhecimento que surge com a proposta de auxiliar, por meio do seu sistema de regras e princípios, na dissolução de problemas éticos à vida humana e ao desenvolvimento da tecnologia.

Sobre a sua gênese, Alarcón (2004, p.152) afirma que o conceito de bioética foi utilizado, pela primeira vez, por Vans Rensselaer Potter, biólogo da Universidade de Wisconsin, em 1971, no livro intitulado "Bioéthics: bridge to the future", com o sentido de "ser a ciência responsável pela participação racional, porém cautelosa, no processo de evolução biológica e cultural".

Por conseguinte, foi Warren Reich, na obra "Encyclopedia of bioethics" em 1978, o primeiro autor que afirmou a dimensão sanitária e de ética na científica da bioética ao considerá-la como o estudo sistematizado da conduta humana, examinada à luz dos princípios e valores morais, na área da ciência da vida e da atenção à saúde (NAMBA, 2015, p. 9)

De certo, percebe-se que a palavra bioética é um neologismo derivado das palavras gregas bios (vida) e ethike (ética). Pode-se defini-la como o estudo sistemático das dimensões morais - incluindo visão, decisão, conduta e normas morais - das ciências da vida e da saúde, utilizando uma variedade de metodologias éticas num contexto interdisciplinar. (PASSINI, p.27, 2006).

A bioética, portanto, é um conceito de grande amplitude, que abrange ciência, política, direito e ética, está em constante evolução e representa um estudo acerca da conduta humana no campo da vida, da saúde humana e do perigo da interferência nesse campo pelos avanços das pesquisas biomédicas e tecnocientíficas (FABRIZ, 2003, p. 75).

Para além de uma nova ética científica, a bioética tem influência na reflexão jusfilosófica acerca dos direitos individuais e coletivos em saúde e na noção de autonomia, o que se reflete nas críticas à faceta paternalista da medicina e na desconstrução do mito da autoridade médica (PORTO, 2014, p. 214) e, por isso, a bioética é um campo de reflexão que também questiona o poder instituído.

Os conflitos práticos e as temáticas específicas da bioética também apresentam uma dimensão política em sua matéria. Nesse sentido, é notória uma dicotomia argumentativa 109 | Revista Brasileira de Direito Animal, e -issn: 2317-4552, Salvador, volume 15, n. 02, p.107-119, Mai - Ago 2020 
composta por ideais conversadores e liberais, os quais objetivam exprimir o que é importante evitar, promover e apoiar no avanço da biotecnociência como um todo e na extensão prática do estudo da bioética.

Os posicionamentos conservadores, conforme demonstra Namba (2015, p.12), são constituídos, em geral, por: i) rejeitar a liberdade do indivíduo como dimensão principal e objeto dos avanços das técnicas; ii) considerar os problemas individuais e sociais provocados por novas tecnologias, as quais devem ser aplicadas com cautela se não forem devidamente controladas e conhecidas em suas consequências; iii) julgar importante a cautela e necessário aprofundar o conhecimento sobre as técnicas antes de adentrar em campos pouco explorados.

De igual maneira, Namba $(2015$, p.13) esclarece que os liberais defendem que: i) o indivíduo está acima do caráter público e social, portanto é seu único agente moral; ii) a liberdade individual se sobrepõe à regulação e imposições restritivas estatais; iii) é imperiosa a resolução pacífica de conflitos, com formas jurídicas para tolerâncias e aceitação de casos diversos, bem como considera o homem, enquanto indivíduo, o fim da técnica e dos avanços da biotecnociência.

Percebe-se que a questão central das discussões políticas da bioética consistem no debate público da proteção ao direito de liberdade de escolha do indivíduo em oposição à regulamentação das liberdades individuais e dos avanços do conhecimento científico pela moralidade pública e, por conseguinte, pelos instrumentos normativos estabilizadores de conduta apresentados pelo Direito.

Assim, aproxima-se das mais importantes discussões bioéticas a corrente denominada transhumanismo, que prega a melhoria das características humanas e o rompimento dos limites biológicos, por meio do uso da tecnologia e da ciência a serviço dos desejos de humanos de dominar a mente, o corpo e seus processos químicos com intuito de superar sofrimentos involuntários como a velhice, as deficiências e a morte.

É pertinente, portanto, afirmar que se aproxima uma "era biotecnológica" que alterará os tradicionais dilemas do debate sobre a moralidade e implicará em buscar respostas sobre a obrigação do homem para com os novos sujeitos criados por meio desse avanço tecnológico, assim denominados de sujeitos pós-humanos (VILAÇA E DIAS, 2014, p. 342).

A forma de vida pós-humana se apresenta como seres originalmente evoluídos ou desenvolvidos a partir de seres humanos, mas diferentes em seu aspecto significativo, conforme afirma Savalescu (apud VILAÇA E DIAS, 2014, p. 342). Tal mudança no estatuto especista ocorre, ou ocorrerá pela aplicação de técnicas de manipulação, instrumentalização ou artificiação da vida.

A bioética e o transhumanismo se apresentam como as mais atuais discussões sobre o futuro da comunidade humana, aliado ao progresso da ciência e do uso ético das tecnologias. Logo, são temas que se aproximam e refletem discussões sobre uma moralidade do que está por vir, de um futuro que já está sendo construído pelo avanço da ciência e da tecnologia para atender as necessidades humanas e a vontade de estabelecer novos limites biológicos.

Sobre esse debate específico, apresenta-se também uma dicotomia entre o entendimento dos bioconservadores, com posicionamentos anti-melhoramento e proteção ao que se entende como natureza humana da atualidade historicamente constituída, e os transhumanistas, que defendem uma ideia de avanço da ciência aliado aos interesses do melhoramento humano em, com liberdade individual para sua utilização e superação dos limites da biologia humana (VILAÇA E DIAS, 2014, p.343).

$\mathrm{Na}$ oportunidade, pela pretensão desse trabalho, insta apresentar com maior detalhe a discussão bioética proporcionada pelo transhumanismo, sua concepção, conceito, princípios, 
principais características e os impactos desse novo cenário caracterizado pelo avanço biotecnológico, a possibilidade de melhoramentos das capacidades humanas e a superação dos seus limites biológicos.

\section{Transhumanismo e o sujeito pós-humano}

Nesse novo cenário, marcado pela incidência de mais relações tecnológicas e pela tentativa de prevalência da ciência sobre temas políticos e problemas socioculturais, o homem demonstra maior domínio sobre questões antes consideradas como imprevisíveis, sendo possível mitigar crises como o surgimento de pestes, a excessiva fome, grandes guerras e fenômenos da natureza, (HARARI, 2015, p. 09).

Esse domínio tecnocientífico sobre fenômenos naturais, políticos e sociais, antes incontroláveis, possibilitou a comunidade humana enveredar esforços para o desenvolvimento da ciência e alcançar o progresso em temas que buscam a melhoria do bem-estar geral, qualidade de vida e superação de problemas ligados à saúde.

Dessa maneira, uma nova agenda científica se impõe, a qual busca incessantemente a chave para a felicidade e realização dos desejos humanos em sua esfera individual, com propósitos gerais ligados a temas como o domínio da vida, da reprodução e da morte, o progresso da técnica aliado a estética, a manipulação bioquímica humana, o surgimento de novas drogas e terapias para aprimorar habilidades e curar doenças.

Nesse âmbito, o transhumanismo surge como uma filosofia moderna que pretende oferecer diretrizes para alcançar uma denominada condição pós-humana. O seu expoente pensador é Max More que apresenta na obra "Transhumanism - Towards a Futurist Philosophy" (1990) os fundamentos da corrente que conjuga os valores do humanismo, da racionalidade, do cientificismo, o compromisso pelo progresso e a valorização da existência (pós) humana (MORE apud VILAÇA e DIAS, 2014, p.345).

A filosofia transhumanista se apresenta, para além de um projeto ideológico, uma revisitação ao iluminismo, com viés secularista e biológico, que não busca mais superar as amarras da superstição e do religioso, mas sim os limites do biológico por meio da razão, da ciência e da tecnologia para eliminar doença, melhorar o corpo e a mente e superar a morte (YOUNG apud VILAÇA e MOURA, 2014, p. 345).

O transhumanismo apresenta, como um dos seus mais importantes documentos, a Declaração Transhumanista (1998), que elenca diretrizes e princípios da filosofia transhumanista, dentre os quais se destacam: a aceitação de um futuro tecnocientífico para a humanidade; a ampliação do potencial humano para superar questões que trazem sofrimento involuntário, como o envelhecimento e as deficiências; a prevenção do uso indevido da tecnologia; a redução de riscos existenciais e meios de desenvolvimento para preservação da vida; a criação políticas públicas baseadas em uma visão moral de responsabilidade e de respeito para com as gerações futuras; a defesa do bem estar dos seres sencientes, inclusive intelectos artificiais; a autonomia e ampla escolha pessoal sobre como as pessoas desejam viver suas vidas.

O transhumanismo constitui-se uma visão científica e axiológica criteriosa, que segundo Bostrom (apud VILAÇA e DIAS, 2014, p. 348) é uma corrente que defende o contexto póshumano com condições básicas de segurança global, progresso tecnológico, pragmatismocientífico, amplo acesso as oportunidades oferecidas pela tecnociência, liberdade para alteração

111 | Revista Brasileira de Direito Animal, e -issn: 2317-4552, Salvador, volume 15, n. 02, p.107-119, Mai - Ago 2020 
da natureza biológica, morfológica e reprodutiva do homem, ampliação da inteligência, defesa da diversidade, respeito a todas as vidas sencientes e prolongação da vida.

Assim, trata-se de um movimento que sustenta uma nova fase evolutiva da humanidade em qual se fusionam homem e maquinas transformando-os em uma espécie hibrida, um projeto de desejo que busca aumentar as capacidades humanas (PONTEL e RONCHETTI, 2020, p.01).

Todavia, o transhumanismo também apresenta críticas pertinentes, como o otimismo tecnológico, agravamento das desigualdades e exclusão social, a afetação das relações humanas, o desaparecimento de culturas, o interesse econômico sobre o desenvolvimento biotecnológico e a utilização desses avanços com finalidade bélica.

É um cenário que começa a ser desenhado, perceptível a partir do momento em que o ser humano, dispondo do domínio de todo aparato tecnológico, científico e informacional, apresenta-se com a pretensão de desafiar os mitos do divino, como da onisciência e imortalidade. Segundo Harari (2015, p. 37), a elevação dos seres humanos à condição de deuses se dará em decorrência dos avanços da engenharia biológica, a engenharia de seres nãoorgânicos e engenharia cibernética.

A engenharia biológica não pretende mais aguardar a dinâmica do processo de seleção natural e se apresenta disposta a realizar todas as modificações necessárias para melhorar as qualidades humanas, como o aprimoramento genético e o controle dos ciclos bioquímicos, já a engenharia de seres não-orgânicos propaga a ideia do avanço tecnológico e a criação de seres com inteligência artificial e livres da limitação físico-orgânica chamados robôs (HARARI, 2015, p. 37).

A engenharia cibernética, por outro lado, se propõem a colocar o corpo orgânico humano em simbiose com estruturas biônicas, como próteses, olhos artificiais e nano-robôs, o que poderia oferecer capacidades maiores do que as comuns a um corpo orgânico dito normal, criando um novo sujeito, fruto do hibridismo homem-robô, denominado ciborgue (HARARI, 2015, p. 37).

É da junção da engenharia biológica e da engenharia cibernética que surge o termo biohacking, o qual, de acordo com Covarrubias (2020, p.89), trata-se da utilização da própria biologia com uma série de técnicas médicas, nutricionais e eletrônicas com o objetivo de ampliar as capacidades físicas e mentais do sujeito, ou seja, é um meio de autodeterminação da vontade e que pode resultar no desenvolvimento de um transhumanista e na figura do ciborgue.

A superação de barreiras biológicas, com novas interfaces entre cérebro e computador, a extensão radical da vida, a erradicação de doenças incuráveis, a melhoria das capacidades mentais, a superação de deficiências corporais e a diminuição de limitações funcionais e incapacitantes por meio da tecnologia biônica são exemplos de que os limites da natureza humana estão sendo redesenhados e profundamente afetados pela ciência e pela tecnologia (DIAS E VILAÇA, 2014, p.344).

É nesse cenário que desponta a figura do ciborgue, imagem culturalmente construída nas obras de ficção científica, na literatura e no cinema, e que passa a fazer parte do cotidiano humano atual. Esse termo, criado na década de 1960 por Nathan Kline e Manfred E. Clines, se dá pela junção de "cybernetics" e "organism" e resulta em "cyborg", foi criado com o intuito de referir-se a uma nova classe de humanos capazes de sobreviver aos mais diversificados meios (KIM, 2004, p. 208). Desse modo, complementa Thierry Hoquet (2019, p. 37):

"Uma primeira definição de ciborgue o identifica como um amálgama tecnohumano: a combinação entre um ser humano e um arsenal técnico

112 | Revista Brasileira de Direito Animal, e -issn: 2317-4552, Salvador, volume 15, n. 02, p.107-119, Mai - Ago 2020 
integrado. O ciborgue surge então como uma figura limite, uma das maneiras com o qual o século xx pensou o hibrido".

A noção geral dessa figura é de que constitui-se de um organismo dotado de partes orgânicas e cibernéticas e que utiliza a tecnologia artificial com a finalidade de melhorar as capacidades humanas, É um homem biônico, ou ser humano que possui implantes sintéticos, que aumentariam seu desempenho físico e mental (RAMA, 2012, p. 64).

O ciborgue, portanto, não é uma máquina, mas sim um organismo dirigido e governado por um mecanismo homeostático e motivado pelas mesmas forças que atuam sobre as máquinas e pelos homens, criando um organismo autoconsciente de natureza orgânica e cibernética em equilíbrio (HOQUET, 2019, p. 33).

Sendo assim, cumpre reservar tópico específico para dissertar sobre a cultura cibernética, o bionismo, a constituição da figura do ciborgue e também sobre o atual panorama biotecnológico.

\section{Cibercultura e a ideia do ciborgue}

A presença do ciborgue no mundo moderno é uma realidade que impõe uma nova relação entre homem e máquina, dinâmica esta que merece atenção e análise, pois implica em novas construções sociais e culturais. De certo, o avanço da tecnológica mudou e continua a modificar os hábitos humanos, sua cultura e seu convívio em sociedade, uma vez que apresenta conceitos e ideias novas, como a biônica e a cibernética, cruciais para compreensão ampla da cibercultura e sua constituição.

O bionismo, conhecido como campo de pesquisa emergente, é ciência biomimética e investiga o funcionamento dos sistemas vivos e busca reproduzir os truques da natureza em artefatos sintéticos, é um dos responsáveis pela criação do ciborgue como produto cultural dessa nova ordem biotecnológica (KIM, 2004, p.208).

Já a cibernética, conceito científico artificialmente criado por Norbert Wiener, surge com a ideia fundamental de que certas funções de processamento e controle de informações são semelhantes em máquinas e seres vivos, pois equivalente e redutíveis a um mesmo modelo e lei matemática (KIM, 2004, p. 200).

Nesse contexto, o sincretismo entre a tecnologia cibernética e os corpos humanos criam um novo personagem da contemporaneidade que é a figura do ciborgue. O ciborgue é um híbrido maquina-organismo, uma criatura da realidade social e também da ficção (HARAWAY, 2000, p.36).

É uma criatura pós-humana, fruto de um processo de eletrificação e mecanização dos seres humanos e, concomitantemente, humanização e subjetivação das máquinas (TADEU. 2000, p. 12). O ciborgue, por sua vez, concatena conceitos da cibernética e do bionismo, e apresentase como fruto do pensamento utilitarista que anuncia a imagem de um homem melhorado, com acoplagem de tecnologia e com limitações menores do que aquelas impostas pela natureza (KIM, 2004, p. 210).

Segundo Thierry Hoquet (2019, p.318) a figura do ciborgue é acompanhada de um projeto da busca por superar o humano, como uma rampa que leva aos estímulos da melhoria e alteração do corpo, as novas possibilidades ofertadas pela tecnologia.

$\mathrm{Na}$ literatura, a construção do ciborgue e do ser pós-humano é descrita em diversas obras, como, por exemplo, no mito grego de Ícaro e nas obras Frankstein (1819) de Mary 
Shelley; O homem que fora consumido (1843) de Edgar Allan Poe; e Eu, robô (1950) e O homem bicentenário (1976) de Isaac Asimov.

No cinema, os ciborgues sempre são retratados com certa desconfiança sobre suas pretensões, como nas obras Blade Runner (1982) e Robocop (1987). Sobre a questão afirma Rama (2012, p. 69) que a figura do ciborgue é utilizada na literatura e no cinema para nos fazer refletir sobre as nossas relações com as máquinas cotidianas e computadores, que já se tornaram extensão dos corpos humanos e que impossibilita estabelecer a fronteira de independência entre homem e máquina.

A arte, por sua vez, também trás reflexões por meio das intervenções de artista como em Stelios Arcadios, que apresentam performances ligadas a alta tecnologia, ao futurismo, transhumanismo e a constituição do sujeito pós-humano, que implicam em provocações sobre o que é humano, o que nos caracteriza como tal, a necessidade da superação dos corpos biológicos e os sentimentos humanos (RAMA, 2012, p. 71).

Dessa maneira, a vulgarização da cibernética ocorreu por influência artística da corrente que se denomina "cyberpunk", que disseminou os estereótipos que a cibercultura apresenta nos dias atuais, como na imagem do homem-gadjet, cujo corpo é marcado pelo suporte de instrumentos biônicos que lhe caracterizam um traços tecnológicos de vida futurista (KIM, 2004, p.212).

$\mathrm{Na}$ vida real, a medicina, o interesse mercadológico e as pretensões militares impulsionaram os estudos ligados ao desenvolvimento de organismos vivos acoplados a alta tecnologia. Cumpre salientar que a tecnologia do ciborgue se apresentam de quatro maneiras de intervenção, conforme defende Gray, Mentor e Figeroa-Sarriera (apud TADEU, 2000 p.12):

"1. restauradoras: permitem restaurar funções e substituir órgãos e membros perdidos; 2 . normalizadoras: retornam as criaturas a uma indiferente normalidade; 3. reconfiguradoras: criam criaturas póshumanas que são iguais aos seres humanos e, ao mesmo tempo, diferentes deles; 4. melhoradoras: criam criaturas melhoradas, relativamente ao ser humano."

Dessa maneira, a medicina proporcionou experiências e avanços consideráveis em busca da melhoria da qualidade de vida do homem, como a criação de próteses tecnológicas, mecanismos de reabilitação e implantes biônicos que substituem uma função orgânica, como andar, ouvir, pulsar sangue ou correr.

Além disso, o interesse mercantil de explorar um segmento de alta complexidade e elevados custos desperta a atenção de grandes conglomerados de capital para a injeção de recursos em pesquisas que tratam sobre a criação de ciborgues e de variáveis que os viabilizem, para efetivar seus usos no cotidiano humano.

A pretensão militarista vai além de querer recuperar bons soldados, os quais sofreram acidentes em campo de batalha e se submetem a procedimentos de reabilitação, como exoesqueletos, e a implantação de próteses bélicas que oferecem maior desempenho no campo de batalha.

Implica ainda assinalar que a sofisticada indústria da guerra, adota também combinações ciborgues entre humanos e máquinas, como por exemplo, ao pilotar aeronaves militares e drones, uma vez que os tempos de resposta e os aparelhos sensórios de simples e "puros" humanos são inadequados para as demandas do combate aéreo supersônico (KUNZRU, 2000, p. 126).

114 | Revista Brasileira de Direito Animal, e -issn: 2317-4552, Salvador, volume 15, n. 02, p.107-119, Mai - Ago 2020 
Sobre esse panorama, importa também adentrar, de modo mais detalhado, na aproximação existente entre a cibercultura, os avanços da tecnologia e os interesses das pessoas com deficiência em alcançar melhorias na qualidade de vida e também benefícios que as redimensionem sua importância no espaço social.

\section{Cibertecnologia e a pessoa com deficiência}

As pessoas com deficiência, nos mais diversos momentos históricos, sempre receberam tratamento excludente e depreciativo por grande parte das sociedades, as quais, geralmente, rejeitavam completamente ou as integravam socialmente com muita timidez, pautadas em políticas caritativistas, religiosas ou assistencialistas de modo incipientes a suprir as necessidades de sua efetiva inclusão social (NEUMANN e ALGERICH apud ALENCAR, 2017, p. 107).

Em um contexto mais recente cresceu o interesse para o estudo da deficiência e da busca da qualidade de vida dessas pessoas, o que repercutiu em importantes avanços nas áreas do saber como a medicina de reabilitação e na criação de direitos das pessoas com deficiência, os quais foram especialmente impulsionados pelos movimentos sociais ao longo dos anos de seu desenvolvimento.

Nesse sentido, os avanços biotecnocientíficos possibilitaram significativas mudanças no tratamento dessas pessoas, com a criação de próteses com maior nível de tecnologia, como por exemplo, juntas pélvicas artificiais, implantes de tímpanos para os surdos, implantes de retina para os cegos e todo o tipo de cirurgia cosmética que fazem parte, hoje, do repertório médico (KUNZRU, 2000, p.126).

Além disso, criou um paradigma médico-tecnológico capaz de realizar intervenções que possibilitam criar seres com poderes e habilidades sobre-humanas. Essa conjuntura é real e pode ser constatada nos atletas paraolímpicos que conseguem, com o auxílio de suas próteses supertecnologicas, alcançar recordes, metas e números de modo superior aos atletas ditos normais.

A possibilidade do melhoramento humano assusta a grande maioria dos interlocutores da bioética, uma vez que se defendem o progresso regrado e ético da biotecnologia, e, além disso, requerem um uso equilibrado e moralmente correto das possibilidades científicas.

Entretanto, o debate sobre o melhoramento das habilidades e capacidades humanas apresenta um espectro moral indissociável. Como assinala Vilaça e Dias (2014, p. 350), a discussão sobre a melhoria do corpo humano por meio da tecnologia questiona o que é o humano, o que é e como fazer lhe o bem, e qual ideia de futuro deve ser diretriz das condutas éticas-humanas em relação a tecnologia.

Nesse cenário, bioconservadores temem pela instrumentalização da biologia humana e prezam pela proteção da essência humana, e futuristas-transhumanistas pregam a superação dos limites biológicos como forma de melhorar o humano em todas as suas dimensões a fim de oferecer possibilidades de florescimento humano (VILAÇA e DIAS, 2014, p. 350).

Faz-se crucial compreender a questão da liberdade morfológica, categoria criada para discutir aspectos ligados ao direito de modificar o próprio corpo e que apresenta uma dimensão individualista sobre a possibilidade de intervir e de mudar aspectos ligados à sua própria natureza.

Surge a ideia da uma dignidade pós-humana, percepção afirmada por aqueles que pretendem conceder um reconhecimento moral ao grupo de pessoas biotecnologicamente modificados e de dar autonomia a pretensão de buscar melhorias a sua condição biológica, 
restando ao Estado apenas realizar incursões na liberdade morfológica e reprodutiva individuais nos casos de abusos de direito que cause prejuízo a outras pessoas (BOSTROM, 2005, p.10).

Esse paradigma futurista também recria problemas sociais já conhecidos como o estigma e preconceito, os quais incidiriam sobre as pessoas que não se submeteram deliberadamente aos procedimentos de modificação pós-humana, questionando uma escolha moralmente ruim ou um exercício da liberdade morfológica (SANDEL apud VILAÇA e DIAS, 2014, p. 349).

De certo, o estigma e o preconceito são associados "naturalmente" associados as pessoas com deficiência física, condição essa que reflete dor e sofrimento psíquico e físicos. Os avanços tecnológicos e a criação de mecanismos de reabilitação avançados são vistos com muita esperança pela comunidade de pessoas com deficiências, as quais almejam uma nova experiência de vida, distante da segregação e da discriminação.

Nesse sentido, os avanços da ciência e da medicina com finalidade de intervenção para implantação de mecanismos ciborgues em pessoas com deficiência possibilitarão uma reconfiguração de um status desse segmento, os quais, antes sujeitos a invisibilidade social e rotulados com suas incapacidades, receberiam um novo estatuto jurídico e tornar-se-iam símbolos da condição pós-humana, do corpo orgânico potencializado pela máquina.

É um alerta que Joon Ho Kim (2013, p.262) sobre a superação do estigma da deficiência pela reconstrução biocibernética do corpo, que, concomitantemente, reforça o paradigma da normatização dos corpos sadios e afeta diretamente o a concepção de corpos humanos, com a estereotipação de pessoas com deficiências físicas que apresentam sua organicidade modificada.

Nesse sentido, a maneira de retratar as pessoas com deficiência modificar-se-á da visão de cobaias ou objetos de caridade, pois vistas como socialmente mortas, sem papel a desempenhar e uma invisibilidade social (HAVEY apud KIM, 2013, p. 262) para serem compreendidas como sujeitos com vantagens cibernéticas em relação aos demais.

O status de humano-ciborgue protetizado reflete uma imagem de boa reabilitação, transformam essas pessoas em sujeitos socialmente aceitos, fruto de um processo que resulta na normalização dos corpos deficientes por meio da biônica e flexibilização de um padrão de beleza dominante (KIM, 2013, p. 285).

O corpo cibernético promete também aumentar as capacidades humanas, como tem se evidenciado nas próteses de para-atletismo esportivas, que oferecem melhores velocidades na prática do esporte, nos exoesqueletos, que ofertam maior força e nos dispositivos orgânicos, como implante coclear, marca-passo e a prótese cardíaca, e olhos cibernéticos.

Por isso, é crescente as discussões sobre a consolidação, como um direito humano, de ter um corpo humano ciborgue, potencializando o aperfeiçoamento individual e o direito de intervenção no próprio corpo e trazem questionamentos relevantes sobre a necessidade de intervenção tecnológica no processo evolutivo da espécie humana (FORNASIER e OLIVEIRA, 2020, p. 63)

As vantagens das intervenções tecnológicas aparentam ser imensas e, com frequência, se manifestam com um discurso otimista, entretanto, é necessário produzir reflexões que questionem o valor moral dessas escolhas pós-humana e a sua afetação a perspectiva de dignidade humana, bem como incitar o debate sobre a ampliação dessa dignidade para as pessoas que buscam a melhoria genética, cibernética e tecnológica.

\section{Conclusão}

116 | Revista Brasileira de Direito Animal, e -issn: 2317-4552, Salvador, volume 15, n. 02, p.107-119, Mai - Ago 2020 
Mediante a argumentação exposta é possível afirmar que compete à bioética, como ramo de conhecimento, tornar-se, com maior enfaticidade e popularização, a disciplina central responsável por disciplinar os limites da ciência. De certo, a popularização da reflexão bioética amplia os horizontes para a construção de um futuro desejável à toda comunidade humana e criado a partir de um contexto ético-participativo e sem influências políticas que reneguem progresso que promove o bem comum.

Ademais, constata-se que o transhumanismo destaca-se como uma corrente políticaideológica atraente à uma grande parte de seres humanos que mantêm a esperança de superar seus limites biológicos do corpo e da mente, como as pessoas com deficiência, as pessoas com doenças que causam sofrimento involuntário e aos cientistas que desejam testar os limites da biotecnociencia aplicada ao homem e ao sujeito pós-humano.

Além disso, evidenciou-se que o sujeito pós-humano encontra sua gênese na figura do ciborgue, construída historicamente com o auxilio da literatura, do cinema e da arte, e que reflete em sentimentos dúbios de esperanças e receios quanto a independência da relação homem-máquina, ao hibridismo biotecnológico e a sua natureza moral.

Por fim, salienta-se também que as pessoas com deficiência podem se tornar grandes beneficiados dos avanços tecnológicos e científicos da medicina reabilitacional, entretanto importa existir uma necessária atenção com temas ainda pouco debatidos como, por exemplo, o valor simbólico das intervenções médicas-tecnológicas, os dilema relacionado com a alteração corporal por meio da tecnologia, a liberdade morfológica e a construção da dignidade póshumana.

\section{Referências}

ALARCÓN, Pietro de Jesús Lora. Patrimônio Genético Humano e a sua proteção na Constituição Federal de 1988. São Paulo: Editora Método, 2004.

ALENCAR, Evandro Luan de Mattos. A pessoa com deficiência no discurso constitucional brasileiro. In: XXVI Encontro Nacional do CONPEDI, 2017, Brasília, DF. Anais (on-line). Florianópolis, CONPEDI, 2017.2 Disponível em https://www.conpedi.org.br/publicacoes/roj0xn13/2070z86p. Acesso em 18 mai. 2020.

BOSTROM, N.; SAVULESCU, J. Human enhancement ethics: The state of the debate. FABRIZ, Daury Cesar. Bioética e Direitos Fundamentais: A bioconstituição como paradigma do biodireito. Belo Horizonte: Editora Mandamentos, 2003.

BOSTROM, Nick. Em defesa da dignidade pós-humana. Bioethics, v. 19, n. 3, p. 01-12, 2005.

COVARRUBIAS, Jersain Z. Llamas. Derechos Humanos, Transhumanismo y posthumanismo: una mejora tecnológica humana. Derechos Fundamentales a Debate, n. 12, p.85-104, 2020.

FORNASIER, Mateus de Oliveira; KNEBEL, Norberto Milton Paiva. APERFEIÇOAR O CORPO É UM DIREITO HUMANO? o pós-humano transhumanista sob a ética dos sujeitos nômades e a metáfora ciborgue. Revista Húmus, v. 10, n. 28, 2020. 
GRAY, Chris H.; MENTOR, Steven; FIGUEROA-SARRIERA, Heidij. Cyborgology. Constructing the Knowledge of Cybernetic Organisms. In: Gray, Chris H.; Figueroa-Sarriera, Heidi J.; Mentor, Steven (Orgs.). The cyborg handbook. Nova York: Routledge, 1995.

HARARI, Yuval Noah. Homo-Deus: Uma breve história do amanhã. São Paulo: Ed. Companhia das Letras, 2015.

HARAWAY, Donna. Manifesto ciborgue. In: KUNZRU, Hari; HARAWAY, Donna; SILVA, Tomaz Tadeu da (Org.). Antropologia do Ciborgue: as vertigens do pós-humano. Belo Horizonte: Autêntica, 2000.

HOQUET, Thierry. Filosofia ciborgue: pensar contra os dualismos. São Paulo: Ed. Perspectiva, 2019.

KIM, Joon Ho. Cibérnetica, ciborgues e ciberespaço: notas sobre as origens da cibernética e sua reinvenção cultural. Revista Horizontes Antropológicos. Porto Alegre/RS, ano 10, n.21, jan-jun, p. 199-219, 2004.

KIM, Joon Ho. $\mathrm{O}$ estigma da deficiência física e o paradigma da reconstrução biocibernética do corpo. 2013. 513 f. Tese (Doutorado em Antropologia Social) - Faculdade de Filosofia, Letras e Ciências Humanas, Universidade de São Paulo, São Paulo, 2013.

KUNZRU, Hari. "Você é um ciborgue?": um encontro com Donna Haraway. In: KUNZRU, Hari; HARAWAY, Donna; SILVA, Tomaz Tadeu da (Org.). Antropologia do Ciborgue: as vertigens do pós-humano. Belo Horizonte: Autêntica, 2000.

KUNZRU, Hari. Genealogia do ciborgue. In: KUNZRU, Hari; HARAWAY, Donna; SILVA, Tomaz Tadeu da (Org.). Antropologia do Ciborgue: as vertigens do pós-humano. Belo Horizonte: Autêntica, 2000.

McCONVILLE, Mike; CHUI, Wing Hong. Research methods for law. Edinburgh: Edinburgh University Press. 2007.

MORE, M. Transhumanism: toward a futurist Philosophy, 1990. Disponível em: http:// www.maxmore.com/transhum.htm. Acesso em: 18 mai. 2020.

NAMBA, Edison Tetsuzo. Manual de bioética e biodireito. 2a ed. São Paulo: Editora Atlas, 2015.

NEUMANN, Katiúscia e ALGERICH, Eloisa Nair de Andrade. A situação da pessoa com deficiência em relação à sociedade, ontem e hoje. Revista Direito em Debate, v.13, n.21, 2004.

PESSINI, Léo. Bioética: um grito por dignidade de viver. São Paulo: Editora Paulinas, 2006.

PONTEL, Evandro; RONCHETTI, Ricardo. Entrevista basada en la conferencia del Rabino Dr. Fishel Szlajen,"Inteligencia Artificial y Transhumanismo: falacias del humano exacerbado y desfondado en la tecnologia", en el IV Coloquio de Bioética de la PUCRS (2019). Veritas (Porto Alegre), v. 65, n. 1, p. 36050, 2020.

118 | Revista Brasileira de Direito Animal, e -issn: 2317-4552, Salvador, volume 15, n. 02, p.107-119, Mai - Ago 2020 
PORTO, Dora. Bioética na América Latina: desafio ao poder hegemônico. Revista Bioética, v. 22, n. 2, p. 213-224, 2014.

RAMA, Jander Luiz. Homem-máquina: desconfianças de um corpo pós-humano. Revista-Valise, v. 2, n. 3, p. 63-74, 2012.

SANDEL, Michael. Contra a perfeição: ética na era da engenharia genética. Tradução de Ana Carolina Mesquita. Rio de Janeiro: Civilização Brasileira, 2013.

SAVULESCU, J. The human prejudice and the moral status of enhanced beings: what do we owe the Gods?. In: SAVULESCU, J.; BOSTROM, N. (Eds.). Human enhancement. Oxford: Oxford University Press, 2009.

SEVERINO, Antonio Joaquim. Metodologia do Trabalho Científico. 23a ed. São Paulo: Cortez Editora, 2010.

SILVA, Tomaz Tadeu da. Nós, ciborgues: o corpo elétrico e a dissolução do humano. In: KUNZRU, Hari; HARAWAY, Donna; SILVA, Tomaz Tadeu da (Org.). Antropologia do Ciborgue: as vertigens do pós-humano. Belo Horizonte: Autêntica, 2000.

VILAÇA, Murilo Mariano; DIAS, Maria Clara Marques. Transumanismo e o futuro (pós-) humano. Physis: Revista de Saúde Coletiva, v. 24, p. 341-362, 2014.

YOUNG, S. Designer evolution: a transhumanist manifesto. New York: Prometheus Books, 2006. 